\title{
Federal policies fuel spread of swine flu, experts say
}

$\mathrm{L}$ ongstanding federal strategies and polices have exacerbated the rapid spread of Novel A(H1N1) influenza in remote First Nations communities, public health officials and aboriginal health experts charge.

The federal government is unprepared to adequately manage or even accurately quantify the incidence among Aboriginal people, the experts add.

The pandemic's extraordinary penetration of remote communities in the Canadian north is a reflection of federal social policies, says Chief Medical Officer of Health for Nunavut Isaac Sobol.

Although as many as 30 federal agencies manage social policies for Aboriginal people, there is still rampant malnutrition and overcrowded housing, Sobol says, noting that up to 18 people share small houses in some Nunavut communities, with people using beds in shifts.

Little wonder infectious diseases such as tuberculosis are nine times more prevalent in Nunavut than the rest of Canada, Sobol adds. "It's common sense that these conditions provide a breeding ground for the spread of disease. And that helps explain why the transmission of novel H1N1 has been phenomenally efficient."

Sobol notes that 405 of Nunavut's 31000 residents had confirmed cases of swine flu, as of July 15, with 40 requiring hospitalization. Public Health Agency of Canada (PHAC) data pegged that slightly lower, at 390 cases, with the median age of patients being nine years, "significantly younger" than elsewhere in Canada. The Nunavut numbers began spiralling in mid-June, when surveillance measures were intensified.

Insufficient federal funding leaves Nunavut unable to do the epidemiological work required to assess who should get the vaccine, once it becomes available, Sobol says. "There may not be the science to determine who is the most vulnerable. Successive Canadian governments have not wanted to highlight

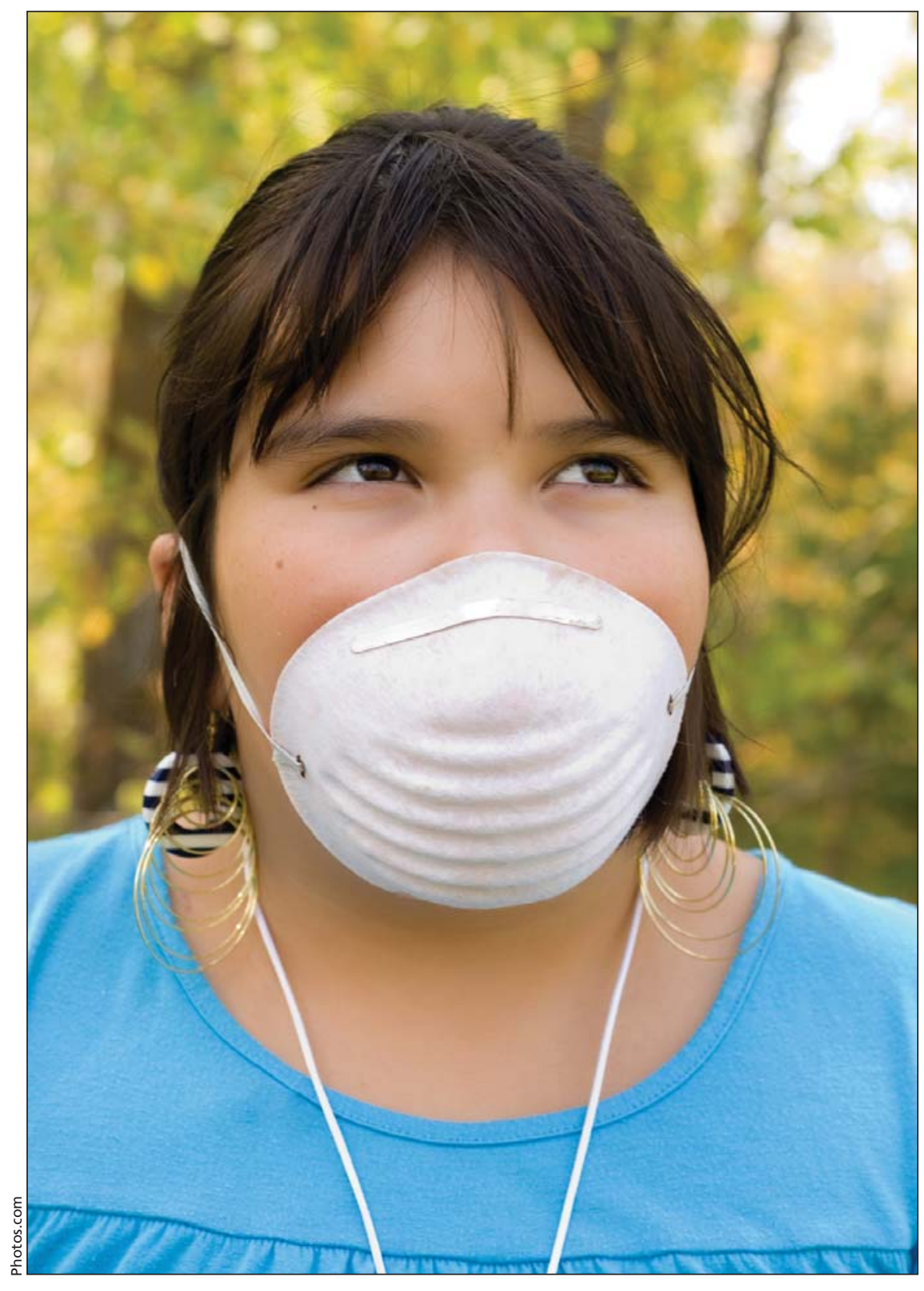

The federal government is unprepared to adequately manage or even accurately quantify the incidence of H1N1 influenza among Aboriginal people, experts say.

the situation concerning Inuit and Aboriginal health. We see the results now with Novel H1N1."

The situation is no less grim in other parts of Canada, including Ontario, Manitoba and Saskatchewan, where the pandemic spread rapidly through First
Nations communities and similar criticisms have surfaced regarding neglect of primary health care and surveillance.

Aboriginal people have been disproportionately afflicted, Assembly of First Nations Public Health Advisor Kim Barker says, adding that PHAC 
did not disaggregate aboriginal cases from its pandemic data until mid-July.

As of July 15, PHAC had only identified 559 cases among Inuit, Metis and First Nations people, including 139 cases in Manitoba, Barker says. Yet Manitoba officials pegged their province's total as being at least three times higher. In St Theresa Point alone, 550 people reported flu symptoms and 100 were flown out to larger centres.

Barker and other experts, such as Bruce Minore, research director for the Centre for Rural and Northern Health Research at Lakehead University in Thunder Bay, Ont., say the gaps and inconsistencies in federal data are a major issue when it comes to crafting adequate responses to disease outbreaks.

Health assessment data at the community level is particularly problematic, adds Janet Smylie. "H1N1 is an example of the kind of disaster that can happen when you have this kind of an inadequate surveillance system."

The situation may improve as PHAC recently indicated it will revise the system to collect data based on physicians' reporting of flu-like symptoms, rather than confirmed cases.

"Counting confirmed cases no longer serves a useful public health purpose," explains Dr. David Butler Jones, Canada's Chief Medical Officer of Health. PHAC now has difficulty getting case data on individuals "if it comes from the provinces or territories. Each jurisdiction is different," he says, adding that isolated communities are particularly challenging.
There have also been regional variations in response to outbreaks. In Ontario, for example, First Nations leaders were advised to reconsider planned community gatherings and the province stepped up anti-viral distribution on reserves. "We watched what happened in Manitoba, and we acted," says Dr. Donald Low, medical director of health laboratories for the Ontario Agency for Health Protection and Promotion.

Barker says it's clear from recent events that federal aboriginal health care officials are unprepared for a more virulent outbreak, should Novel $\mathrm{A}(\mathrm{H} 1 \mathrm{~N} 1)$ re-assort.

Health Canada spokesman Stephane Shank, though, says the department is closely monitoring the situation and has already allocated $\$ 6.5$ million over five years, (about $\$ 1$ annually per capita) to support pandemic preparedness activities among First Nation communities. "Most of these funds were used to address the areas of surge capacity; strengthening federal public health capacity; and emergency preparedness, planning, training and integration in on reserve First Nation communities."

Elise Weiss, Manitoba's acting chief provincial public health officer, and Butler-Jones also indicated that it's uncertain whether the high incidence of swine flu among Aboriginal people is a function of genetics or environmental conditions.

It warrants further study, as does the role of "underlying risk factors such as diabetes, smoking and overcrowded housing," says Butler-Jones. "The spread of infection is much easier when you are living in close proximity. Sometimes it's just a matter of being in the wrong place at the wrong time."

Margo Greenwood, a University of Northern BC researcher who coordinated a recent study of aboriginal children's health for UNICEF, says a lack of federal investment in primary health infrastructure has contributed to high TB rates among the Inuit, aboriginal infant mortality rates up to eight times higher, and aboriginal immunization rates $20 \%$ lower, than the national average.

"The facts are no longer surprising," she says. "What's surprising is that we haven't moved on it."

Others say the problem lies in Health Canada's unwillingness to invest more money in primary care measures like nursing stations on reserves.

Although the department spends as much as $30 \%$ of community health budgets in some regions for air transport, it will not invest in primary care other than health promotion and disease prevention programs, says Chris Ashton, a consultant specializing in federal expenditures on aboriginal health.

Barker finds it equally disturbing that the federal government appears to be trying to impose some form of gag order on aboriginal people regarding their concerns about the pandemic. "Because the solutions are costly, we are getting a lot of push back from the federal government telling us not to talk about it," she says. - Paul Webster, Toronto, Ont.

DOI:10.1503/cmaj.091355 